\title{
THE RISK OF SMOKING WITH STROKE IN ASIA: META-ANALYSIS
}

\author{
Fadhilatul Hasnah $^{1 *}$,Yuniar Lestari ${ }^{1}$, Abdiana ${ }^{1}$ \\ ${ }^{1}$ Departemen Ilmu Kesehatan Masyarakat, Fakultas Kedokteran, Universitas Andalas, Indonesia \\ *Correspondence email : fhasnah5@gmail.com
}

\begin{abstract}
This study uses a systematic method of review and meta-analysis to look at the risk of smoking with stroke in Asia. Further analysis based on the stroke subtype (ischemic stroke and haemorrhagic stroke was also carried out. Literature search was carried out in the PubMed, EBSCO and Google Scholar databases. Q tests were performed to determine the heterogeneity of included studies. Funnel plot, Egger regression test and trim and fill methods were used to identified publication bias and with the transformation of the model between the fixed effect model and the random effect model for sensitivity analysis A total of 12 articles were included consisting of 9 studies with case control design studies and 3 studies with cohort designs. The meta-analysis results showed that people who smoke have risks pooled OR 2.04 times (95\% CI 1.57-2.65) for having a stroke Analysis of the type of stroke, smokers had 2.3 times the risk of having an ischemic stroke or 2.77 times for having a haemorrhagic stroke. Eggers test showed no influence of publication bias on the meta-analysis of smoking with stroke to. From this meta-analysis, it can be concluded that smoking increasing risk for stroke. This study found the risk of smokers to have a haemorrhagic stroke is higher than ischemic stroke.
\end{abstract}

Keywords: Smoking; Stroke; Meta-analysis

\section{INTRODUCTION}

Stroke is a serious health problem in Asia. A total of 15 Asian countries entered the 50 countries with the highest average deaths from stroke in 2017. Indonesia ranked first followed by Mongolia in third and North Korea ranked fourth. The 2017 Global Burden of Disease Study estimates that strokes will remain second in 2040 as a cause of death in the world. Therefore, the global burden of stroke and stroke-related deaths cannot be reduced substantially without interventions in Asia. ${ }^{1}$

Smoking is a risk factor for stroke. The number of smokers around the world now reaches 1.2 billion people and 800 million of them are in developing countries. According to The Tobacco Atlas 3rd edition, (2009), 57\% percent of smokers are in the Asian region. Indonesia is the third country with the largest number of smokers in the world after China and India. In 2030 it is estimated that the death rate of smokers in the world will reach 10 million, and $70 \%$ of them come from developing countries. ${ }^{1}$

The increase in cigarette consumption has an impact on the increasing burden of diseases caused by smoking and the increase in mortality due to smoking, including stroke. At present $50 \%$ of deaths from smoking are in developing countries. ${ }^{2}$ If this trend continues, around 650 million people will be killed by cigarettes. ${ }^{2}$ An estimated increase in smoking risk factors allows an increase in the incidence of stroke in Asia.

\section{MATERIAL AND METHODS}

This study uses a systematic method of review and meta-analysis to assess the risk of smoking with stroke in Asia. The metaanalysis research was conducted guided by the Meta-analysis of Observational Studies in Epidemiology (MOOSE). Relevant studies are selected using established criteria. Two groups of researchers were 
involved in this study. The first group of researchers is tasked with searching the research literature, selecting research and extracting data from relevant literature. The second group is tasked with evaluating the research included in the meta-analysis. Discussions are conducted to resolve discrepancies and gaps.

\section{Systematic literature search}

Literature search was performed on the PubMed, EBSCO and Google Scholar databases. The keywords used are $(((($ Stroke $)$ OR Ischemic OR Haemorrhagic) OR observational study OR Cohort OR Casecontrol OR Follow Up OR Prospective) AND Risk factors OR Smoking OR Tobacco OR Cigarette)))). The limited article year is 19952019.

\section{Inclusion and exclusion criteria.}

The research article was included if it met the following criteria: 1) the study looked at the relationship between smoking and stroke, 2) the location of the study in the Asian region, 3) the study design of the cohort or case control article, 4) English language, 5) available in the form of full text, 6) there is enough data to process. The research article is excluded if: 1) research with death outcomes due to stroke or reoccurent stroke, 2) duplicated studies or previously published studies.

\section{Data Selection and data extraction}

Literature selection is done in stages. The first selection is done by searching the relevant article title. The relevant article titles are then selected based on the abstract. Research with relevant abstracts is then selected based on information available in full text. The literature taken is carefully reviewed, and various information is extracted for each study examined, including the name of the researcher, the design of the research study, the location of the study, the number of samples, the number of cases, and the risk factors studied.

\section{Data Analysis}

Heterogeneity test is done with the Q test. If I $250 \%$ and $\mathrm{P}<0.05$, then the statistical analysis method used is the random effect model method. If $\mathrm{I} \leq 50 \%$ and P> 0.05, then the fixed effect model statistical method is used to combine studies. Egger regression test was used to identify publication bias. The sensitivity test is done by comparing the results of statistical analysis between the random effect model and the random effect model. The trim and fill approach is used to estimate the central value of the funnel plot to enable stability assessments of all systematic reviews. Data analysis was performed using RevMan software version 5 and publication bias analysis was performed using CMA software version 3 .

\section{RESULTS \\ Research Selection}

Literature identification from the database produced 2543 articles. Overall, as many as 2271 articles were excluded because they were not relevant to the research topic, so as many as 272 articles were relevant by title. These articles were then selected based on abstracts with the results of 235 articles excluded because they did not examine the risk factors referred to in this study, outside the Asian region and study designs other than cohort and case control, so that only 37 articles were relevant based on abstracts. Full text based selection was done on the article and resulted in 25 articles excluded due to lack of data listed for analysis. The final selection results obtained 12 relevant articles to do a meta-analysis (Figure 1). 


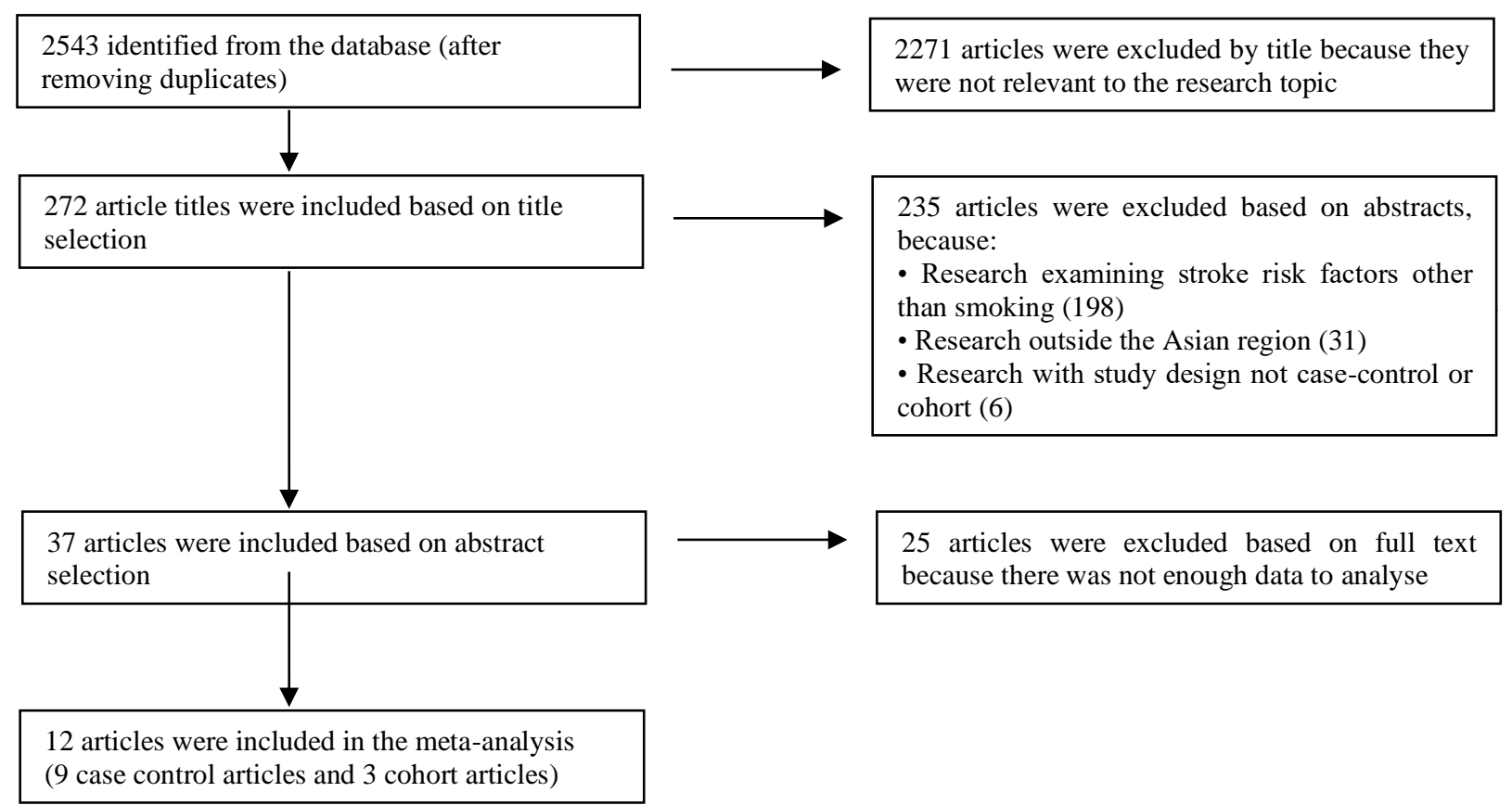

Figure 1. Study selection diagram

Table 1. Research literatur characteristic

\begin{tabular}{|c|c|c|c|c|c|c|c|c|}
\hline No & $\begin{array}{l}\text { Researcher name } \\
\text { (Published Year) }\end{array}$ & $\begin{array}{l}\text { Research } \\
\text { Design }\end{array}$ & $\begin{array}{l}\text { Research } \\
\text { location }\end{array}$ & $\begin{array}{l}\text { Number of } \\
\text { Sample }\end{array}$ & Sex & $\begin{array}{l}\text { Mean } \\
\text { Age, } y\end{array}$ & $\begin{array}{l}\text { Number } \\
\text { of Cases }\end{array}$ & Type of Stroke \\
\hline 1 & Mannami $(2004)^{3}$ & cohort & Japan & 41282 & $\begin{array}{l}\text { Men and } \\
\text { Women }\end{array}$ & $40-59$ year & 1149 & $\begin{array}{l}\text { All stroke } \\
\text { Ischemic } \\
\text { Haemorrhagic }\end{array}$ \\
\hline 2 & Yamagishi (2003) ${ }^{4}$ & Cohort & Japan & 3626 & Men & 40-69 year & 257 & $\begin{array}{l}\text { All stroke } \\
\text { ischemic } \\
\text { Haemorrhagic }\end{array}$ \\
\hline 3 & Kelly $(2008)^{5}$ & cohort & China & 158666 & $\begin{array}{l}\text { Men and } \\
\text { Women }\end{array}$ & $\geq 40$ year & 6780 & All stroke \\
\hline 4 & Bi $(2010)^{6}$ & Case-control & China & 14248 & NR & $35-45$ year & 1988 & All stroke \\
\hline 5 & Sharmin $(2017)^{7}$ & Case-control & Bangladesh & 100 & NR & $\mathrm{NR}$ & 50 & ischemic stroke \\
\hline 6 & Shah $(2013)^{8}$ & Case-control & Pakistan & 150 & NR & NR & 50 & All stroke \\
\hline 7 & Sorganvi (2014) ${ }^{9}$ & Case-control & India & 200 & NR & $\begin{array}{l}30-\geq 80 \\
\text { year }\end{array}$ & 100 & All stroke \\
\hline 8 & El- Hajj $(2019)^{10}$ & Case-control & Lebanon & 650 & NR & $\geq 18$ year & 205 & $\begin{array}{l}\text { All stroke } \\
\text { ischemic } \\
\text { Haemorrhagic }\end{array}$ \\
\hline 9 & El- Hajj (2017) ${ }^{11}$ & Case-control & Lebanon & 732 & NR & $\geq 18$ year & 202 & All stroke \\
\hline 10 & Feigin (1998) ${ }^{12}$ & Case-control & Rusia & 474 & $\begin{array}{l}\text { Men and } \\
\text { Women }\end{array}$ & NR & 237 & All stroke \\
\hline 11 & Ismail (2010) ${ }^{13}$ & Case-control & Iraq & 346 & NR & NR & 173 & $\begin{array}{l}\text { All stroke } \\
\text { ischemic } \\
\text { Haemorrhagic }\end{array}$ \\
\hline 12 & Bandasak (2011) ${ }^{14}$ & Case-control & Thailand & 196 & NR & $15-45$ year & 98 & stroke \\
\hline
\end{tabular}

\section{Research Charateristic}

This study analyzes data based on what was reported in a research article. A total of
12 articles were included consisting of 9 studies with case-control study designs and 3 studies with cohort designs. The smallest 
number of cases as many as 50 to the most 6780 analyzed in this study. A total of 4 articles reported outcomes in both ischemic stroke and hemorrhagic stroke. One study examined ischemic stroke outcomes (Table 1)

\section{The relationship between smoking and stroke}

A total of 12 articles were combined to analyze the risk of smoking with stroke in Asia. Heterogeneity test showed that the research variation was heterogeneous with a $p$ value of 0.05 lower that is $p<0.00001$ and the variation value between studies (I2) was 95 . The results of the meta-analysis obtained pooled odds ratio of 2.04 (95\% CI 1, 57-2.65) with $\mathrm{p}<0.00001)$. For further exploration, an analysis is performed based on the type of stroke. The analysis results obtained pooled odds ratio each of 2.30 (95\% CI 1.54-4.45) for ischemic stroke and 2.77 (95\% CI 1.41-5.43) for hemorrhagic stroke with a $\mathrm{p}$ value $<0.05$ i.e. $\mathrm{p}<0.00001$ and $\mathrm{p}<0.003$ (Figure 2 and 3).

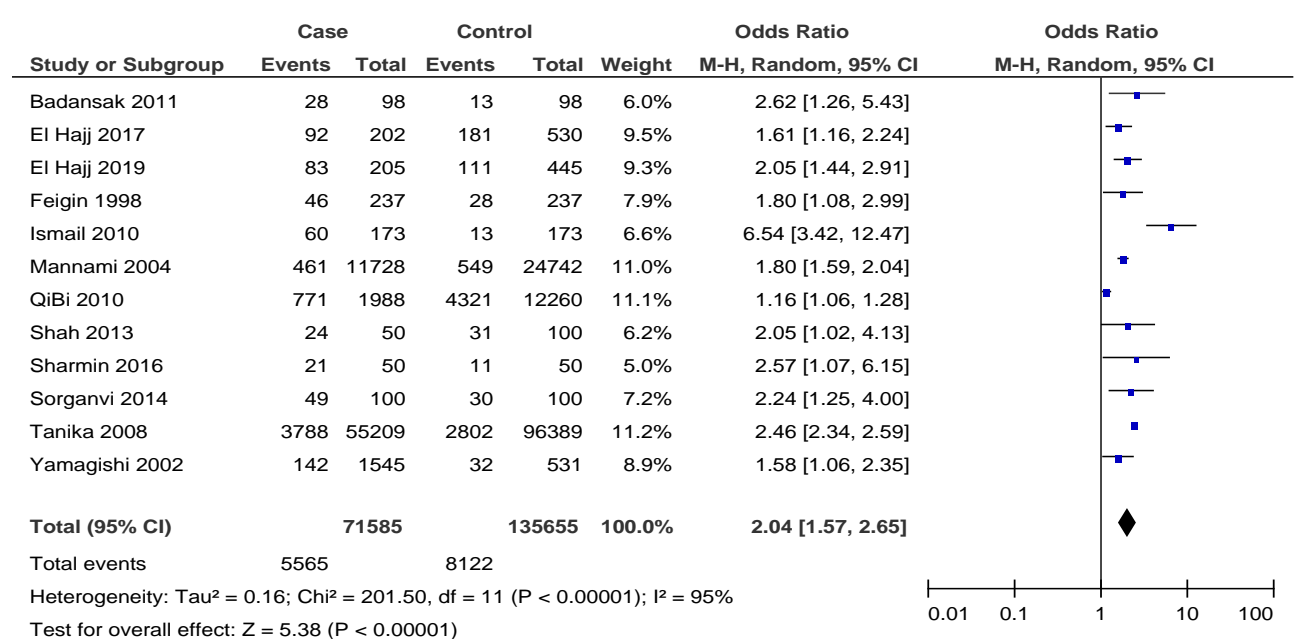

Figure 2. Forest plots the risk of smoking with stroke

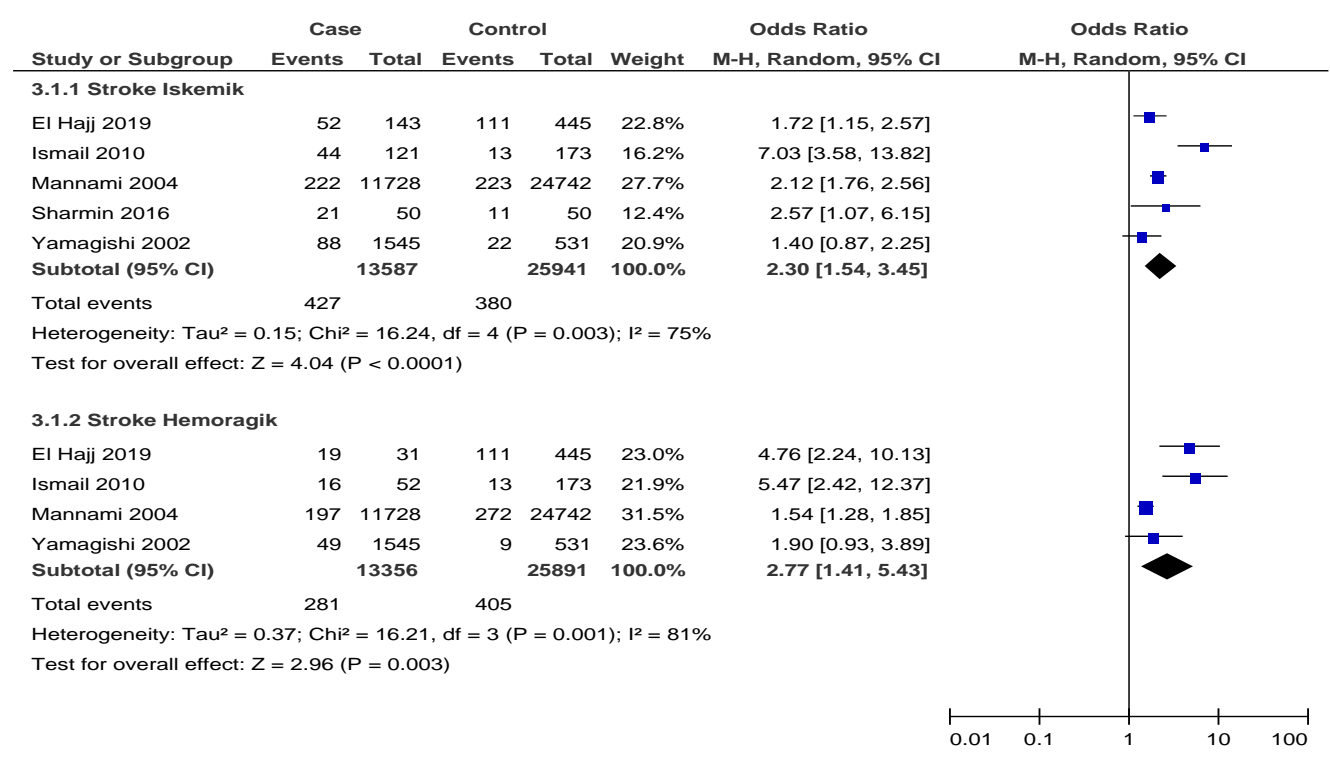

Figure 3. Forest plots the risk of smoking with ischemic stroke and hemorrhagic stroke 


\section{Publication bias}

Funnel plot and Eggers test were carried out to detect the effect of publication bias. Funnel plot shows a sismmetric shape, so it was concluded that there was no influence of publication bias on the meta-analysis of smoking with stroke. This is reinforced by the

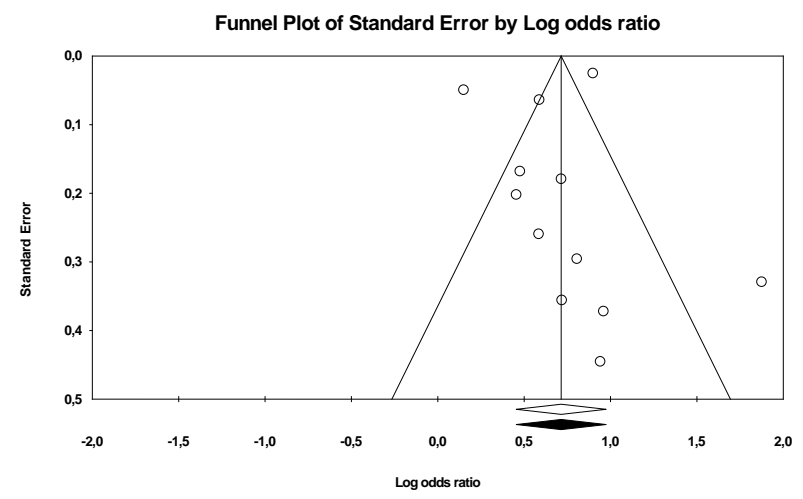

Figure 4. Trim and fill meta-analysis of smoking with stroke

\section{Sensitivity Test}

Sensitivity test results showed fairly consistent results in the meta-analysis of smoking with stroke. There were no results of the Eggers test which shows the results of $\mathrm{t}$-intercept equal to zero, namely $\mathrm{t}=$ $-0,77585$. Trim and fill using the missing article assumption with a small effect size of the mean effect shows no difference between pooled OR before and after trim and fill (Figure 4).

Table 2. Sensitivity Test

\begin{tabular}{cccc}
\hline Research Variable & $\boldsymbol{p}$ value heterogeneity & Fixed Effect Model & Random Effect Model \\
\hline Smoking & $\mathrm{P}<0,00001$ & $2,06(1,98-2,15)$ & $2,04(1,57-2,65)$ \\
\hline
\end{tabular}

\section{DISCUSSION}

The total number of participants in the risk analysis of smoking with stroke was 207,240 participants, which was the total participants of all articles combined. The results of a smoking meta-analysis with stroke showed that smokers were 2.04 times more likely to suffer a stroke than nonsmokers. The analysis based on the stroke subtype shows that smokers are 2.3 times more likely to have an ischemic stroke than nonsmokers and 2.77 times more likely to have a hemorrhagic stroke than nonsmokers.

Several meta-analyzes of the risk of smoking with stroke have been conducted. One of them by Pan, et al (2019) included as many as 14 research articles with the results of the study showing the significance of smoking with stroke with a pooled odds ratio significant differences in the pooled OR fixed effect model or random effect model (Table 2). 
These effects increase the risk of ischemic stroke. While the mechanism between smoking and the risk of haemorrhagic stroke is uncertain. ${ }^{3}$

In addition to cigarette smoke, some of the literature included in this meta-analysis states that the number of cigarettes and duration of smoking also triggers strokes in smokers. Several other studies report that the more cigarette consumption, the higher the risk of stroke, including research by Mannami (2004), El Hajj (2019) and Tanika (2008). Research by Mannami (2004), Yamagishi (2002), Tanika (2008), Sorganvi (2014) and El Hajj (2019), reported the risk of smoking with stroke if consuming cigarettes $>20$ cigarettes / day.

In contrast to other meta-analyzes of the risk of smoking with stroke, this metaanalysis focuses on the risk of smoking with stroke with a focus on Asian countries. The results of this meta-analysis show that smoking significantly increases the risk of stroke in both ischemic and hemorrhagic strokes. Although not analyzed further in this meta-analysis, the findings from some of the combined literature can be concluded that the number of cigarettes consumed by smokers daily also increases the risk of stroke in smokers.

There are several limitations in this study. First, the heterogeneity observed in this metaanalysis is the result of different participant characteristics and different definitions of risk factors. Second, combining the two types of research designs becomes its own shortcomings in this analysis. Third, strokes can be grouped into various types. But in this meta-analysis, only the ischemic stroke and hemorrhagic stroke types are discussed.

\section{CONCLUSION}

From this meta-analysis, it can be concluded that smoking increases the risk of stroke in Asian people. This study found the risk of smokers to experience a hemorrhagic stroke is higher than ischemic stroke. Additional sources of literature and research searches with larger samples and more detailed information are needed for further analysis.

\section{REFERENCES}

1. Mehndiratta MM, Khan M, Mehndiratta P, Wasay M. Stroke in Asia: geographical variations and temporal trends. Journal of Neurology, Neurosurgery \& Psychiatry. 2014;85(12):1308

2. Kementerian Kesehatan RI. Perilaku Merokok Masyarakat Indonesia. RI IPDDIKK, editor. Jakarta.2013. 12 hal p.

3. Toshifumi M, Hiroyasu I, Shoichiro B. Cigarette Smoking and Risk of Stroke and Its Subtyes among Middle-Aged Japanese Men and Women. AHA Journal. 2004;35(6):1248-3

4. Yamagishi K, Iso H, Kitamura A, Sankai T, Tanigawa T, Naito Y, et al. Smoking raises the risk of total and ischemic strokes in hypertensive men. Hypertension research : official journal of the Japanese Society of Hypertension. 2003;26(3):209-17.

5. Kelly TN, Gu D, Chen J, Huang J-F, Chen J-C, Duan X, et al. Cigarette smoking and risk of stroke in the chinese adult population. Stroke. 2008;39(6):1688-93.

6. Bi Q, Wang L, Li X, Song Z. Risk factors and treatment of stroke in Chinese young adults. Neurological research. 2010;32(4):366-70.

7. Sharmin N, Rahman Z, Yusuf DMA, Rahman N. Risk of Smoking in the Causation of Ischemic Stroke: Experience of 100 Cases in Bangladesh. European Journal of Preventive Medicine. 2017;4:132-5.

8. Shah SM, Shah SM, Khan S, Rehman S, Khan Z, Ahmed W, et al. "Addressing the impact of stroke risk factors in a case control study in tertiary care hospitals": a case control study in Tertiary Care Hospitals of Peshawar, Khyber 
Phukhtoonkhwa (KPK) Pakistan. BMC research notes. 2013;6:268.

9. Sorganvi V, Kulkarni M, Kadeli D, Atharga S. Risk factors for stroke: A case control study. International Journal of Current Research and Review. 2014;6(3):46.

10. El-Hajj M, Salameh P, Rachidi S, AlHajje A, Hosseini H. Cigarette and Waterpipe Smoking are Associated with the Risk of Stroke in Lebanon. Journal of epidemiology and global health. 2019;9(1):62-70.

11. El-Hajj M, Salameh P, Rachidi S, AlHajje A, Lahoud N, Hassan H. Stroke risk factors: a hospital-based casecontrol study in Lebanon. JR Soc Med Open. 2017;8(6):1-10.

12. Feigin VL, Wiebers DO, Nikitin YP, O'Fallon WM, Whisnant JP. Risk factors for ischemic stroke in a Russian community: a population-based casecontrol study. Stroke. 1998;29(1):34-9.

13. Ismail K, Al-Tawil N, Al-Hadithi $\mathrm{T}$. Risk Factors for Stroke in Erbil City: A Case-Control Study. Zanco J Med Sci. 2010;14:90-6.

14. Bandasak R, Narksawat K, Tangkanakul C, Chinvarun Y, Siri S. Association between hypertension and stroke among young Thai adults in Bangkok, Thailand. Southeast Asian Journal of Tropical Medicineand Public Health. 2011;42(5):1241.

15. Pan B, Jin X, Jun L, Qiu S, Zheng Q, Pan M. The Relationship Between Smoking And Stroke : A Meta-analysis. Medicine. 2019;98(12):e14872

16. Hackshaw A, Morris JK, Boniface S, Tang J-L, Milenković D. Low Cigarette Consumption And Risk of Coronary Heart Disease And Stroke : Meta-analysis of 141 Cohort Studies in 55 Study Reports. BMJ. 2018;360:j5855, .

17. AHA/ASA. Guidlines for the Primary Prevention of Stroke 2014. 20-]. Available from: http://ahajournals.org
18. Bhat V, Cole, JW, Sorkin, JD, Wozniak, MA, Malarcher, AM, Giles, WH, Stern, B \& Kittner, SJ. Dose-response relationship between cigarette smoking and risk of ischemic stroke in young women'. Stroke. 2008;39(9):2439-43. 